\title{
BioMedicine
}

Volume 11 | Issue 2

Article 2

2021

\section{Hormones Can Influence Drug Addiction-A Narrative Review}

Follow this and additional works at: https://www.biomedicinej.com/biomedicine

Part of the Life Sciences Commons, and the Medical Sciences Commons (c) (i)

This work is licensed under a Creative Commons Attribution 4.0 License.

\section{Recommended Citation}

karimian, Morteza and Famitafreshi, Hamidreza (2021) "Hormones Can Influence Drug Addiction-A Narrative Review," BioMedicine: Vol. 11 : Iss. 2 , Article 2.

DOI: $10.37796 / 2211-8039.1120$

This Review Articles is brought to you for free and open access by BioMedicine. It has been accepted for inclusion in BioMedicine by an authorized editor of BioMedicine. 


\title{
Hormones can influence drug addiction-A narrative review
}

\author{
Hamidreza Famitafreshi $^{a}$, Morteza Karimian ${ }^{\text {b, } *}$ \\ a Physiology Department, Tehran University of Medical Sciences-International Campus, Tehran, Iran \\ ${ }^{\mathrm{b}}$ Physiology Department, Tehran University of Medical Sciences, Tehran, Iran
}

\begin{abstract}
Drug addiction is a dangerous condition that is the concern of human societies. Nevertheless, several issues exist ahead of people with a drug use disorder during addiction. Accordingly, various types of studies have been conducted to understand better the problems that people with a drug use disorder encountered. People with a drug use disorder usually have a problem tolerating the withdrawal period and some relapse to drug abuse. Complementary studies further revealed that some hormones like oxytocin (OXT), vasopressin, hypothalamic-pituitary-adrenal axis (HPA) axis hormones, sex hormones, thyroid hormones, and nutritional hormones are probably involved in addiction processes. These hormones completely with different mechanisms can influence drug users' ultimate outcome. As we will see, these hormones influence tolerance, sensitization, and compulsive drug seeking and taking behavior. In this review, they have been further discussed.
\end{abstract}

Keywords: Addiction, Withdrawal, Stress, Sex, Hormones, Thyroid, Neurohypophyseal

\section{Introduction}

$\mathrm{D}$ rug addiction is a severe socio-economical problem and plenty of studies have been done to reveal the complex aspects of this problem [1]. The foremost downside that people with a drug use disorder encounter is to progression to uncontrolled use of those substances [2]. The monoaminergic and cholinergic systems are the most important systems for investigating these types of behaviors. In different sets of studies especially with cocaine in human subjects, these brain systems have been shown to be important for modulation of some important neuronal pathways. These are the coeruleo-cortical noradrenergic system that regulates divided and selective attention, the basal forebrain cholinergic system that is important for stimulus detection, and the mesostriatal and mesolimbic dopaminergic systems that are important in rewardregulated behaviors. Psychotropic drugs make some changes in the reward circuit and perhaps another alternative part of the brain that renders individuals to develop full manifestation of uncontrolled addiction [3]. These modifications are the changes in the degree of tolerance, the emergence of sensitization, and changing the affinity of drug-receptors. Accordingly, some hormones such as neurohypophyseal hormones and sex hormones have recently been shown in different studies both in animals and human subjects which will interfere with reward circuit neurons and exert some changes which will make prone individuals with a dangerous addiction. Recent studies recommend that Neurohypophyseal hormones like oxytocin and vasopressin [4], stress hormones [5], and sex hormones [6] will have an affect reward circuit that has been observed in animal and human studies. These hormones can change tolerance, sensitization, and self-administration. It should be noted that

Received 6 August 2020; revised 24 September 2020; accepted 2 November 2020.

Available online 1 June 2021

* Corresponding author at: Department of Physiology, Tehran University of Medical Science, Tehran, Iran. Fax: +009802166419484 .

E-mail address: karimian@tums.ac.ir (M. Karimian). 
study models for investigating behaviors such as sensitization and self-administration are mostly assessed by animal studies and in human studies are sparse [7]. Here we are going to reveal the different aspects of these hormones within the addiction process.

\section{Neurohypophyseal hormones}

The shreds of evidence that support the role of Neurohypophyseal hormones in addiction come from animal studies. After subcutaneously, orally and intracerebroventricularly administration of desglycinamide 9 -vasopressin (DG-AVP), heroin selfadministration in rats was reduced [8]. This action is dependent on the sub-regions of the molecular structure of these hormones because the C-terminal tripeptide of oxytocin (OXT), prolyl-leucyl-glycinamide (PLG) facilitates the acquisition of selfadministration [9]. In a recent study, it has been postulated that alcohol and psychostimulant interfere with vasopressin action on the brain and will result in behavioral abnormalities [10]. Later studies with morphine brought convincing evidence that OXT could interfere with addictive behavior via the reward circuit. The most sensitive areas of the brain are the hippocampus and basal forebrain [11, 12]. The primary proof which shows OXT interacts with the mesolimbic dopaminergic system comes from analgesic treatments with morphine in albino mice [13]. However, later studies suggest that this impact can also be seen with the administration of nonanalgesic doses in animal studies [4]. Also in the presence of nicotine dependence and the emergence of withdrawal signs, after administration of OXT, the severity of withdrawal signs reduces [14]. A study with heroin showed that the primary action of OXT is not reinforcing properties of heroin, but rather on the degree of tolerance and dependence on heroin in rat models [15]. In a recent study with alcohol, OXT blocks enhanced motivation for alcohol abuse through GABAergic transmission in the central amygdala rat model of alcohol dependence [16]. Despite the presence of OXT receptors on limbic areas, it has been suggested that OXT may exert its effects through vasopressin receptors in the brain of male, adult rats [17]. Also, there are pieces of evidence that propose OXT may partly influence addictive behavior through dopamine receptors in the basal forebrain of the mouse [18]. In alternative complementary studies with cocaine and ethanol, it was shown that OXT can interfere with locomotor activity, tolerance, and sensitization in mice models
$[19,20]$. Intranasal treatment of OXT has been suggested for clinical trials and clinical trials for OXT are ongoing as there are many trials in the clinicaltrial.gov database for OXT and different drugs such as alcohol, nicotine, and morphine, but vasopressin in a controlled study showed promising effects for the facilitation of methadone therapy in a clinical trial in human subjects [21].

\section{Stress hormones}

Psychotropic drugs are by themselves are potent stimulators of stress hormone release. The strong evidence for the role of addictive drugs as stimulators of stress hormone release comes from an animal study that showed by a single injection of a bolus dose of Alcohol, the HPA (Hypothalamic-pituitary-adrenal axis) axis will be activated adult male Sprague-Dawley rats [22]. Nevertheless, this effect was mostly seen in acute alcohol administration. However, in chronic ethanol stress, tolerance will occur in the HPA axis that may incline individuals to relapse and heavy drinking [23]. This relapse results mainly through exacerbation of the existing ethanol withdrawal signs in the mouse model [24]. Other studies with alcohol proposed a role for GABAergic receptors in rodents and humans [25]. An experiment for this purpose showed antagonist of the glucocorticoid receptor can precipitate drug-seeking behavior in a stress state in a study with psychostimulant drugs and high alcohol drinkers [26, 27] but in alcoholdependent, individuals reverse occurred [28]. Also, there is another mechanism for relapse that is due to neuroadaptation as the result of the compensatory rise in stress hormones in chronic abusers that predisposes individuals to relapse to drug-seeking behavior in studies with alcohol and cocaine in rodent studies [29-31]. In this sense, a wide variety of differences among individuals as the result of different region dependent-receptors expressions in related brain areas exists that were obtained by rodent studies [32]. In a recent study prefrontal cortex has been shown to be important in this kind of relapse in different studies in animals and human subjects [33]. Also, epigenetic changes in glucocorticoid receptors in related brain areas change addictive behavior that was observed in clinical studies [34, 35]. Epigenetic changes are described as the changes that occur in gene expression as the result of methylation or acetylation without affecting gene sequences. Epigenetic changes are a new interesting topic in this sense and are well described in different studies [36]. 


\section{Sex hormones}

A growing body of evidence suggests that sex hormones are strong mediators of addiction propensity [6, 37]. In animal studies, male rats showed alcohol-dependence quicker than female rats and also recover slower than male rats [38]. Differences in consumption of alcohol were observed that was lower in male compared to female in adolescent and adult Sprague-Dawley rats [39]. Also, sex hormones influence the acquisition, maintenance, and reinstatement that was well observed both in human and rodent studies[40]. In human studies, there are several variations among individuals. Overall women abusers are fewer than men abusers. Meanwhile, it should be considered that this may be dependent on opportunity and chance of access that is occurred as the result of the sex hormones influences that were observed in human studies [41, 42]. On the other hand, women tend to increase the rate of consumption of addictive substances more rapidly than men [43]. Because higher reactivity of women to stress, women find quitting more difficult than men [34]. This difference may be reflected in any stages of addition progression such as acquisition, maintenance, dysregulation-escalation, and relapse. There is evidence that estradiol has a protective role in smoking cessation in women [44]. It is thought estradiol reduces anxiety and enhances positive effects. There is strong evidence that sex hormones influence reward center maturation and efficacy that are well observed in rodent and human studies [45, 46]. However, about the application of testosterone in individuals with substance use disorder further studies are needed. More studies should be done to answer the question that what is the molecular mechanism behind this phenomenon. Based on recent studies, addictive drugs influence different sexes differently that are well documented in different types of human and rodent studies. Based on this finding it can be considered that there is a wide difference among individuals to react to addictive drugs [40].

\section{Thyroid hormone}

Thyroid hormones are essential hormones that are needed for normal bodily functions. Thyroid dysfunction is a common finding in alcoholism. Subclinical and clinical hypothyroidism may result in the development of depression and cognitive impairment. These cognitive and mood abnormalities increase the risk of relapse to addiction. It should be noted that there are great differences among individuals in this sense [47]. Although there are great controversies about the TSH (thyroid-stimulating hormone) changes in addiction, several studies indicate TSH changes that result in the alternation of T3 and T4 although there are studies that there has been an alternation of T3 and T4 without any significant change of TSH [48]. Some studies suggest the importance of thyroid hormone replacement for successful anti-smoking treatment that results in better cognitive function that is necessary for successful treatment [49]. Some studies suggest the direct toxic effect of addictive drugs on thyroid function that result in compensatory activation of the hypothalamic-pituitary axis with an increase in TRH (thyrotrophin-releasing hormone) secretion. Thyroid hormones are known agents that are used for the improvement of affective disorders [50]. The affective disorders are prevalent in abusers of drugs. In a user of heroin, circulating total thyroxin and triiodothyronine and TBG (thyroxin binding globulin) were increased but reverse triiodothyronine was normal. Human studies also show, there was a diminished response of thyrotrophin to thyrotrophin-releasing hormone and after cessation of heroin, the abnormal levels came back to the normal state [51]. In a narcotic study, the results were slightly different and it was seen that there was a slight increase in total T3 and a decrease in T3RU, and serum-free T4 level was decreased [48]. The decrease in thyroid hormone in drug users may suggest replacement therapy may reverse some aspects of drug side-effects that may interfere with successful treatment especially in heavy users [52]. Animal studies on this topic are limited.

\section{Adipocyte-derived hormones and other nutritional regulators}

Drug addiction is associated with many pathophysiological problems that result in disturbances of nutritional status [53]. Drug addicts usually suffer from malnutrition that often is associated with a lack of food availability [54]. The changes in nutritional intake result in adipose tissue-derived hormones and immune disorders that complicate methadone therapy. In an animal study with methadone, there was a significant abnormality in glucose and lipid profile [55]. The nutritional imbalances may negatively impair methadone therapy in drug abusers. Adipose tissue-derived hormones like leptin, adiponectin, and resistin are hormones that regulate the metabolic state of individuals [56-58]. It is suggested that a far better balance of those hormones helps a person with a drug use disorder to better combat the addiction. In a recent study, it has been shown that in heroin users, basal serum leptin and adiponectin levels were significantly decreased 
while serum resistin concentrations were raised compared to healthy subjects. It has been suggested that these changes are independent of nutritional status and insulin sensitivity among 'individuals' [53]. Another hormone in this topic is $\alpha-\mathrm{MSH}$ one of the hypothalamic melanocortins that regulate food intake [59]. This hormone complicated the opiate maintenance program. This hormone mainly uses for food-craving. $\alpha$-MSH has an antagonistic effect compared to opioids at many loci including the hypothalamus. Similarities between drug and eating addictions have been noted in recent studies. This hormone has recently got a great interest in getting better insight into opioids craving [59].

\section{Methadone therapy and its complications}

Besides the importance of the above hormones in the treatment of untreated addiction, it would be helpful for establishing an effective treatment during methadone therapy, hormonal deregulations as the consequence of methadone therapy to be considered [60, 61]. After methadone therapy, a wide variety of hormonal imbalances develops that has been well observed in human studies. These are included hypogonadism [62], sexual dysfunction [63, 64], decreased testosterone in serum [65], hyperprolactinemia [66], hypercalcitonemia [67], reduction of thyroid hormone secretion, and TSH (Thyroid-stimulating hormone) [68], adverse effect in pregnancy [69], and decreased bone density [70]. Disrespecting these abnormalities during methadone therapy may result in difficulties in reaching a successful treatment. Also, this misunderstanding may cause people with a drug use disorder to relapse to drug use for preventing the concurrence of such undesired side-effects. Some clinical studies have recommended patients may get benefit from hormonal replacement therapy, especially for sexual dysfunction [62]. However, some other clinical studies suggest the application of buprenorphine as the replacement therapy of methadone may reduce the side-effects [71].

\section{Conclusion}

Overall, it can be concluded that neurohypophyseal hormones, stress hormones, and sex hormones can interfere with tolerance, sensitization, and binge intake. About other hormones such as thyroid hormones, more studies should be done to reveal the different aspects of them in different contexts that improve high-risk behavior. Adipocyte-derived hormones seem to have a protective effect in the abstinence period especially in heroin users by improving the nutritional status of the individuals.
Also, different hormonal imbalances during methadone therapy may discourage patients to deal with treatment-related problems that are most relevant to the specific hormonal imbalances that are all mentioned. Therefore, some suggest replacement therapy with hormones that are mentioned to be imbalanced during methadone therapy may encourage individuals to continue treatment. It is possible by considering the above findings more purposeful and promising treatment for patients with a drug use disorder implemented. Also, the level of hormones may predict the outcome of addiction.

\section{Conflict of interest}

None to be declared.

\section{Funding}

This review article has been conducted by personal funding.

\section{References}

[1] Cartwright WS, Solano PL. The economics of public health financing drug abuse treatment services. Health Policy 2003; 66(3):247-60.

[2] Robbins TW, Granon S, Muir J, Durantou F, Harrison A, Everitt B. Neural Systems Underlying Arousal and Attention: Implications for Drug Abuse a. Annals of the New York Academy of Sciences 1998;846(1):222-37.

[3] Koob GF, Le Moal M. Drug addiction, dysregulation of reward, and allostasis. Neuropsychopharmacology 2001; 24(2):97-129.

[4] Kovács GL, Telegdy G. Neurohypophyseal peptides, motivated and drug-induced behaviour. Neuropeptides and brain function, vol. 15. Karger Publishers; 1987. p. 138-74.

[5] Sinha R, Jastreboff AM. Stress as a common risk factor for obesity and addiction. Biological psychiatry 2013;73(9): 827-35.

[6] Fattore L, Melis M, Fadda P, Fratta W. Sex differences in addictive disorders. Frontiers in neuroendocrinology 2014; 35(3):272-84.

[7] Leyton M. Conditioned and sensitized responses to stimulant drugs in humans. Progress in Neuro-Psychopharmacology and Biological Psychiatry 2007;31(8):1601-13.

[8] van Ree JM, de Wied D. Heroin self-administration is under control of vasopressin. Life sciences 1977;21(3):315-9.

[9] Van Ree J. Neurohypophyseal hormones and addiction. CNS Pharmacology Neuropeptides. Elsevier; 1982. p. 199-209.

[10] Godino A, Renard GM. Effects of alcohol and psychostimulants on the vasopressin system: Behavioural implications. Journal of neuroendocrinology 2018;30(8):e12611.

[11] Sawchenko P, Swanson L. Relationship of oxytocin pathways to the control of neuroendocrine and autonomic function. Journal of Steroid Biochemistry 1984;20(6):1500.

[12] De Kloet E, Rotteveel F, Voorhuis TA, Terlou M. Topography of binding sites for neurohypophyseal hormones in rat brain. European journal of pharmacology 1985;110(1):113-9.

[13] Szabo G, Telegdy G. Endogenous oxytocin inhibits morphine tolerance through limbic forebrain oxytocin receptors. Brain research 1988;463(2):284-8.

[14] Manbeck KE, Shelley D, Schmidt CE, Harris AC. Effects of oxytocin on nicotine withdrawal in rats. Pharmacology Biochemistry and Behavior 2014;116:84-9. 
[15] Kovács GL, Van Ree JM. Behaviorally active oxytocin fragments simultaneously attenuate heroin self-administration and tolerance in rats. Life sciences 1985;37(20):1895-900.

[16] Tunstall BJ, Kirson D, Zallar LJ, McConnell SA, Vendruscolo JC, Ho CP, et al. Oxytocin blocks enhanced motivation for alcohol in alcohol dependence and blocks alcohol effects on GABAergic transmission in the central amygdala. PLoS biology 2019;17(4):e2006421.

[17] Tribollet E, Barberis C, Jard S, Dubois-Dauphin M, Dreifuss J. Localization and pharmacological characterization of high affinity binding sites for vasopressin and oxytocin in the rat brain by light microscopic autoradiography. Brain research 1988;442(1):105-18.

[18] Kovács GL, Faludi M, Falkay G, Telegdy G. Peripheral oxytocin treatment modulates central dopamine transmission in the mouse limbic structures. Neurochemistry international 1986;9(4):481-5.

[19] Sim L, Morris M, editors. Activation of c-fos in PVN oxytocin neurons exposed to cocaine and dopamine. Society for Neuroscience Abstracts; 1992.

[20] Szabo G, Kovacs G, Telegdy G. Intraventricular administration of neurohypophyseal hormones interferes with the development of tolerance to ethanol. Acta Physiologica Hungarica 1989;73(1):97-103.

[21] Beek-Verbeek Gv, Fraenkel M, Geerlings P, Van Ree J, Wied Dd. Vasopressin analogue in methadone detoxification of heroin addicts. The Lancet 1979;314(8145):738-9.

[22] Lee S, Selvage D, Hansen K, Rivier C. Site of action of acute alcohol administration in stimulating the rat hypothalamicpituitary-adrenal axis: comparison between the effect of systemic and intracerebroventricular injection of this drug on pituitary and hypothalamic responses. Endocrinology 2004;145(10):4470-9.

[23] Spencer RL, McEwen BS. Adaptation of the hypothalamicpituitary-adrenal axis to chronic ethanol stress. Neuroendocrinology 1990;52(5):481-9.

[24] Roberts AJ, Crabbe JC, Keith LD. Genetic differences in hypothalamic-pituitary-adrenal axis responsiveness to acute ethanol and acute ethanol withdrawal. Brain research 1992; 579(2):296-302.

[25] Morrow AL, Porcu P, Boyd KN, Grant KA. Hypothalamicpituitary-adrenal axis modulation of GABAergic neuroactive steroids influences ethanol sensitivity and drinking behavior. Dialogues in clinical neuroscience 2006;8(4):463.

[26] Marinelli M, Piazza PV. Interaction between glucocorticoid hormones, stress and psychostimulant drugs. European Journal of Neuroscience 2002;16(3):387-94.

[27] Savarese AM, Ozburn AR, Metten P, Schlumbohm JP, Hack WR, LeMoine $\mathrm{K}$, et al. Targeting the glucocorticoid receptor reduces binge-like drinking in High Drinking in the Dark (HDID-1) mice. Alcoholism: Clinical and Experimental Research 2020;44(5):1025-36.

[28] Vendruscolo LF, Estey D, Goodell V, Macshane LG, Logrip ML, Schlosburg JE, et al. Glucocorticoid receptor antagonism decreases alcohol seeking in alcohol-dependent individuals. The Journal of clinical investigation 2015;125(8):3193-7.

[29] Le A, Harding S, Juzytsch W, Watchus J, Shalev U, Shaham Y. The role of corticotrophin-releasing factor in stressinduced relapse to alcohol-seeking behavior in rats. Psychopharmacology 2000;150(3):317-24.

[30] Deroche-Gamonet V, Sillaber I, Aouizerate B, Izawa R, Jaber M, Ghozland S, et al. The glucocorticoid receptor as a potential target to reduce cocaine abuse. Journal of Neuroscience 2003;23(11):4785-90.

[31] Vendruscolo LF, Barbier E, Schlosburg JE, Misra KK, Whitfield TW, Logrip ML, et al. Corticosteroid-dependent plasticity mediates compulsive alcohol drinking in rats. Journal of Neuroscience 2012;32(22):7563-71.

[32] Whitaker AM, Priddy BM, Edwards S, Vendruscolo LF. The Role of Brain Glucocorticoid Systems in Alcohol Dependence. In: Neuropathology of Drug Addictions and Substance Misuse. Elsevier; 2016. p. 610-7.
[33] Schwabe L, Dickinson A, Wolf OT. Stress, habits, and drug addiction: a psychoneuroendocrinological perspective. Experimental and clinical psychopharmacology 2011;19(1):53.

[34] Lynch WJ, Roth ME, Carroll ME. Biological basis of sex differences in drug abuse: preclinical and clinical studies. Psychopharmacology 2002;164(2):121-37.

[35] Gatta E, Grayson DR, Auta J, Saudagar V, Dong E, Chen Y, et al. Genome-wide methylation in alcohol use disorder subjects: implications for an epigenetic regulation of the corticolimbic glucocorticoid receptors (NR3C1). Molecular psychiatry 2019:1-13.

[36] Nestler EJ. Epigenetic mechanisms of drug addiction. Neuropharmacology 2014;76:259-68.

[37] Lenz B, Müller CP, Stoessel C, Sperling W, Biermann T, Hillemacher $\mathrm{T}$, et al. Sex hormone activity in alcohol addiction: integrating organizational and activational effects. Progress in neurobiology 2012;96(1):136-63.

[38] Devaud LL, Chadda R. Sex differences in rats in the development of and recovery from ethanol dependence assessed by changes in seizure susceptibility. Alcoholism: clinical and experimental research 2001;25(11):1689-96.

[39] Varlinskaya EI, Spear LP. Acute ethanol withdrawal (hangover) and social behavior in adolescent and adult male and female Sprague-Dawley rats. Alcoholism: Clinical and Experimental Research 2004;28(1):40-50.

[40] Becker JB, Hu M. Sex differences in drug abuse. Frontiers in neuroendocrinology 2008;29(1):36-47.

[41] Van Etten ML, Anthony JC. Male-female differences in transitions from first drug opportunity to first use: searching for subgroup variation by age, race, region, and urban status. Journal of women's health \& gender-based medicine 2001 10(8):797-804

[42] Etten MLV, Neumark YD, Anthony JC. Male-female differences in the earliest stages of drug involvement. Addiction 1999;94(9):1413-9.

[43] Hernandez-Avila CA, Rounsaville BJ, Kranzler HR. Opioid-, cannabis-and alcohol-dependent women show more rapid progression to substance abuse treatment. Drug and alcohol dependence 2004;74(3):265-72.

[44] Walf AA, Frye CA. A review and update of mechanisms of estrogen in the hippocampus and amygdala for anxiety and depression behavior. Neuropsychopharmacology 2006;31(6): 1097.

[45] Elmer G, Pieper J, Hamilton L, Wise R, Becker J, Arnold A. Sexchromosome genes influence amphetamine potentiation of brain stimulation reward independently of gonadal secretions in mice. Washington, DC: Society for Neuroscience; 2005.

[46] Hedges VL, Staffend NA, Meisel RL. Neural mechanisms of reproduction in females as a predisposing factor for drug addiction. Frontiers in neuroendocrinology 2010;31(2):217-31.

[47] Hermann D, Heinz A, Mann K. Dysregulation of the hypothalamic-pituitary-thyroid axis in alcoholism. Addiction 2002;97(11):1369-81.

[48] Gozashti MH, Mohammadzadeh E, Divsalar K, Shokoohi M. The effect of opium addiction on thyroid function tests. Journal of Diabetes \& Metabolic Disorders 2014;13(1):5.

[49] Leach PT, Gould TJ. Thyroid hormone signaling: Contribution to neural function, cognition, and relationship to nicotine. Neuroscience \& Biobehavioral Reviews 2015;57: 252-63.

[50] Bauer M, Heinz A, Whybrow P. Thyroid hormones, serotonin and mood: of synergy and significance in the adult brain Molecular psychiatry 2002;7(2):140-56.

[51] Chan V, Wang C, Yeung RT. Effects of heroin addiction on thyrotrophin, thyroid hormones and prolactin secretion in men. Clinical endocrinology 1979;10(6):557-65.

[52] Dackis CA, Gold MS. New concepts in cocaine addiction: the dopamine depletion hypothesis. Neuroscience \& Biobehavioral Reviews 1985;9(3):469-77.

[53] Housova J, Wilczek H, Haluzik M, Kremen J, Krizova J, Haluzik M. Adipocyte-derived hormones in heroin addicts: the influence of methadone maintenance treatment. Physiol Res 2005;54(1):73-8. 
[54] Mohs ME, Watson RR, Leonard-Green T. Nutritional effects of marijuana, heroin, cocaine, and nicotine. Journal of the American Dietetic Association 1990;90(9):1261-7.

[55] Tahergorabi Z, Rahmani H, Williams J, Moodi M. The effect of methadone on blood glucose, lipids and glucose-modulating hormones in methadone-dependent Wistar rats. Toxicological Research 2020;36(3):221-6.

[56] Henry BA, Clarke IJ. Adipose tissue hormones and the regulation of food intake. Journal of neuroendocrinology 2008;20(6):842-9.

[57] Jackson MB, Ahima RS. Neuroendocrine and metabolic effects of adipocyte-derived hormones. Clinical science 2006; 110(2):143-52.

[58] Hall J, Roberts R, Vora N. Energy homoeostasis: the roles of adipose tissue-derived hormones, peptide YY and Ghrelin. Obesity facts 2009;2(2):117-25.

[59] Reece AS. Hypothalamic opioid-Melanocortin appetitive balance and addictive craving. Medical hypotheses 2011; 76(1):132-7.

[60] Bawor M, Bami H, Dennis BB, Plater C, Worster A, Varenbut $\mathrm{M}$, et al. Testosterone suppression in opioid users: a systematic review and meta-analysis. Drug and alcohol dependence 2015;149:1-9.

[61] Cunningham $P$. The use of sobriety nutritional therapy in the treatment of opioid addiction. J Addict Res Ther 2016;7(282). 10.4172.

[62] Daniell HW. Narcotic-induced hypogonadism during therapy for heroin addiction. Journal of addictive diseases 2002; 21(4):47-53.

[63] Brown RT, Zueldorff M. Opioid substitution with methadone and buprenorphine: sexual dysfunction as a side effect of therapy. Heroin Addict Relat Clin Probl 2007;9(1):35-44.
[64] Chen W, Li X, Li X, Ling L, Xia Y, Chen J, et al. Erectile dysfunction among male heroin addicts receiving methadone maintenance treatment in Guangdong, China. Journal of addiction medicine 2012;6(3):212-8

[65] Bawor M, Dennis BB, Samaan MC, Plater C, Worster A, Varenbut $M$, et al. Methadone induces testosterone suppression in patients with opioid addiction. Scientific reports 2014;4:6189.

[66] Spasovska Trajanovska A, Vujovic V, Ignjatova L, Janikevik Ivanovska D, Cibisev A. Sexual dysfunction as a side effect of hyperprolactinemia in methadone maintenance therapy. Medical archives 2013;67(1):48-50.

[67] Spagnolli W, Torboli P, Mattarei M, De Venuto G, Marcolla A, Miori R. Calcitonin and prolactin serum levels in heroin addicts: study on a methadone treated group. Drug and alcohol dependence 1987;20(2):143-8.

[68] Vescovi P, Gerra G, Rastelli G, Ceda G, Valenti G. Effect of methadone on TSH and thyroid hormone secretion. Hormone and metabolic research 1984;16(1):53-4.

[69] Bui QQ, Tran MB, West WL. Evidence for hormonal imbalance after methadone treatment in pregnant and pseudopregnant rats. Proceedings of the Society for Experimental Biology and Medicine 1983;173(3):398-407.

[70] Grey A, Rix-Trott K, Horne A, Gamble G, Bolland M, Reid IR. Decreased bone density in men on methadone maintenance therapy. Addiction 2011;106(2):349-54.

[71] Hallinan R, Byrne A, Agho K, McMahon C, Tynan P, Attia J. Erectile dysfunction in men receiving methadone and buprenorphine maintenance treatment. The journal of sexual medicine 2008;5(3):684-92. 